\title{
Comparison of single and dual latent tuberculosis screening strategies before biologic and targeted therapy in patients with rheumatic diseases: a retrospective cohort study
}

\author{
Iris Tang, Ho So *, Lucas Luk, Victor Wong, Steve Pang, Virginia Lao, Ronald Yip
}

\section{A B S T R A C T}

Purpose: Before biologic and targeted synthetic disease-modifying antirheumatic drug (b/tsDMARD) treatment, latent tuberculosis infection (LTBI) screening by tuberculin skin test (TST) or interferon gamma release assay (IGRA) is recommended. However, both tests have reduced reliability in immunosuppressed patients. We investigated whether dual LTBI screening with both tests could reduce the incidence of tuberculosis.

Methods: Consecutive patients receiving $\mathrm{b} / \mathrm{tsDMARDs}$ for rheumatic diseases in a regional hospital were recruited. All patients underwent either TST/IGRA or both. They were categorised into a single or dual testing group and were followed up for at least 6 months. Isoniazid was prescribed if any one test was positive.

Results: In total, 217 patients were included in this study; 121 underwent single LTBI testing and 96 underwent dual testing. Tuberculosis occurred in nine patients in the single testing group and one patient in the dual testing group $(7.4 \%$ vs $1.0 \%, \mathrm{P}=0.045)$. However, the difference was not statistically significant when follow-up duration was considered (log rank test). In total, 71 patients tested
This article was published on $2 \mathrm{Apr}$ 2020 at www.hkmj.org. positive for LTBI with isoniazid treatment $(28.9 \%$ in
the single testing group and $45.8 \%$ in the dual testing group, $\mathrm{P}=0.007)$. Agreement between the IGRA and TST was $74.4 \%$ (Cohen's kappa=0.413); agreement was lower in patients receiving prednisolone. Infliximab use was independently associated with tuberculosis $(\mathrm{P}=0.032)$. Mild isoniazid-related sideeffects occurred in seven patients.

Conclusion: Dual LTBI testing with both TST and IGRA is effective and safe. It might be useful for patients receiving prednisolone at the time of LTBI screening, or if infliximab therapy is anticipated.
Hong Kong Med J 2020;26:111-9
https://doi.org/10.12809/hkmj198165
${ }^{1}$ I Tang, MB, BS, MRCP
${ }^{1}$ H So *, FHKAM (Medicine), MSC
${ }^{1}$ L Luk, MB, BS, MRCP
${ }^{1} \mathrm{~V}$ Wong, $\mathrm{MB}, \mathrm{ChB}, \mathrm{FHKCP}$
${ }^{1} S$ Pang, MB, BS, FHKAM (Medicine)
${ }^{1}$ V Lao, MB, BS, FHKAM (Medicine)
${ }^{2}$ R Yip, MB, ChB, FHKAM (Medicine)
Department of Medicine and Geriatrics, Kwong Wah Hospital, Yaumatei, Hong Kong
2 Tung Wah Group Hospitals Integrated Diagnostic and Medical Centre, Yaumatei, Hong Kong
* Corresponding author: h99097668@hotmail.com

New knowledge added by this study

- Dual latent tuberculosis infection (LTBI) screening with the tuberculin skin test and interferon gamma release assay was safe and effective for reducing the incidence of tuberculosis among patients with rheumatic diseases receiving biologic and targeted synthetic disease-modifying antirheumatic drugs in an endemic area.

- Infliximab use was significantly associated with the development of tuberculosis.

- The level of agreement between the tuberculin skin test and interferon gamma release assay was moderate, and may have been affected by ongoing prednisolone or leflunomide treatment at the time of LTBI screening.

Implications for clinical practice or policy

- Dual LTBI screening should be strongly considered in patients with rheumatic diseases receiving immunosuppressants at the time of LTBI screening, when either test result is equivocal, or when use of infliximab is anticipated.

- Patients undergoing treatment with biologic and targeted synthetic disease-modifying antirheumatic drugs should receive education regarding possible symptoms associated with tuberculosis, and should be encouraged to seek medical attention when such symptoms arise.

\section{Introduction}

Management of rheumatic diseases such as rheumatoid arthritis, psoriatic arthritis, and spondyloarthropathy has been revolutionised since the emergence of biologic and targeted synthetic disease-modifying antirheumatic drugs 


\section{風濕病患者生物治療和靶向治療前單軌和雙軌潛 伏性肺結核篩查策略的比較：回顧性隊列研究}

鄧因棋、蘇晧、陸枳泊、王德龍、彭顯廷、劉穎雅、葉文龍

目的：使用生物和靶向合成抗風濕藥 (b/tsDMARD) 治療前, 建議通 過結核菌素皮膚試驗（TST）或 $\gamma$ 干擾素釋放試驗（IGRA）篩查潛伏 性結核感染（LTBI）。不過，免疫抑制患者進行這兩種測試時得出的 可靠性較低。本文檢視兩種測試的雙軌LTBI篩查可否減低結核病發病 率。

方法: 納入一所地區醫院進行b/tsDMARDs治療的風濕病患者。所有 患者接受TST、IGRA或同時兩種測試，並將他們分類為單軌或雙軌測 試組及隨訪至少6個月。任何測試呈陽性時會處方異烟肼。

結果：217例患者被納入研究, 121 例進行單軌LTBI測試, 96例進行 雙軌測試。單軌測試組中9例出現結核病, 雙軌測試組中 1 例出現結核 病（7.4\%比 $1.0 \%, \mathrm{P}=0.045$ ）。不過，將隨訪時間（使用 $\log$ rank檢 驗）列入考慮時並無顯著差異。7 1 例異煙肼治療的LTBI呈陽性（單 軌測試組佔 $28.9 \%$ ，雙軌測試組佔 $45.8 \% ， \mathrm{P}=0.007$ ）。IGRA與TST 測試結果的一致性為 $74.4 \% （ \mathrm{kappa}=0.413 ）$, 接受潑尼松龍治療患 者的兩種測試結果的一致性則較低。使用英夫利昔單抗與結核病相關 （ $\mathrm{P}=0.032 ） 。 7$ 例使用異煙肼後出現輕微副作用。

結論：TST和IGRA雙軌LTBI測試是安全有效的, 在LTBI篩查時接受 潑尼松龍治療的患者或預期使用英夫利昔單抗治療的患者可能有用。

(b/tsDMARDs). However, evidence from various trials and registries has shown that these agents are associated with a heightened risk of tuberculosis (TB) or reactivation of latent tuberculosis infection (LTBI). ${ }^{1-4}$ Notably, a meta-analysis showed that patients receiving anti-tumour necrosis factor alpha (anti-TNF- $\alpha$ ) exhibited $a>3$-fold increase in the risk of $\mathrm{TB}^{5}$; analysis of a post-marketing registry in Japan suggested that anti-interleukin- 6 therapy increased the risk of TB to a similar extent. ${ }^{6}$

Screening for LTBI before initiation of $\mathrm{b} / \mathrm{tsDMARD}$ treatment is strongly recommended universally; its importance cannot be overemphasised in TB endemic areas, such as Hong Kong. ${ }^{7-9}$ However, there is no gold standard screening test. Regional guidelines recommend the use of either tuberculin skin test (TST) or interferon gamma release assay (IGRA) for LTBI screening in patients with rheumatic diseases. ${ }^{10}$ The TST measures the delayed hypersensitivity response to tuberculin purified protein derivatives; however, its specificity is limited by cross-reactivity due to previous bacillus Calmette-Guérin vaccination or exposure to non-TB mycobacterium. In contrast, IGRA measures interferon gamma release by TB-specific effector $\mathrm{T}$ cells; this result does not exhibit cross-reactivity related to bacillus Calmette-Guérin or non-TB mycobacterium. However, both tests are known to exhibit reduced reliability in immunosuppressed patients. ${ }^{11,12}$

Agreement between the TST and IGRA has varied among studies. A meta-analysis showed that pooled concordances were $72 \%$ between the QuantiFERON-TB assay and TST, whereas they were $75 \%$ between the T-SPOT.TB and TST. ${ }^{13}$ Our centre in Hong Kong previously investigated the agreement between the TST and IGRA in patients with rheumatic diseases; the results showed that agreement was only fair (Cohen's kappa=0.39).$^{14}$ Therefore, we hypothesised that the use of dual testing with both IGRA and TST might improve sensitivity for detection of LTBI, thus reducing the incidence of TB in patients with rheumatic diseases receiving $b / t s D M A R D s$. Here, we conducted a retrospective cohort study to compare the efficacy of dual testing with both TST and IGRA versus single testing in terms of reducing the incidence of TB among patients with rheumatic diseases in Hong Kong receiving b/tsDMARDs.

\section{Methods}

\section{Patients}

We reviewed the case records of all patients with rheumatic diseases who began receiving $\mathrm{b} / \mathrm{tsDMARDs}$ in a regional rheumatology unit in Hong Kong, during the period from 1 January 2007 to 31 December 2018. The following b/tsDMARDs were included:abatacept, adalimumab, certolizumab, etanercept, golimumab, infliximab, rituximab, secukinumab, tocilizumab, tofacitinib, and ustekinumab. The following rheumatic diseases were included: rheumatoid arthritis, psoriatic arthritis, spondyloarthropathy, Behçet's disease, adult-onset Still's disease, and dermatomyositis. The patients had been diagnosed in accordance with the 2010 American College of Rheumatology/ European League Against Rheumatism classification criteria for rheumatoid arthritis, ${ }^{15}$ the Classification Criteria for Psoriatic Arthritis, ${ }^{16}$ the Assessment of SpondyloArthritis International Society classification criteria, ${ }^{17}$ the 1990 International Study Group criteria for diagnosis of Behçet's disease, ${ }^{18}$ the Yamaguchi criteria for adult Still's disease, ${ }^{19}$ and Bohan and Peter's criteria. ${ }^{20}$ Patients were included if they had undergone LTBI screening and had been followed up for at least 6 months after the initiation of therapy. Patients were excluded if their LTBI screening had been performed elsewhere, if their results were incomplete, or if they were lost to follow-up.

Patients underwent TST assessment alone prior to the commencement of biologic treatment before August 2013. The IGRA was available after August 2013; patients then underwent either single testing by TST or IGRA, or dual testing by both TST 
and IGRA for LTBI screening, at the discretion of the treating rheumatologists. Patients were divided into single testing group (TST or IGRA alone) or dual testing group (both TST and IGRA), according to the LTBI screening test they underwent prior to use of $b / t s D M A R D s$. The following clinical data were collected: age; sex; co-morbidities including diabetes mellitus, chronic kidney/liver/lung disease, and heart failure; indication for use of $\mathrm{b} / \mathrm{tsDMARDs}$; and concurrent use of traditional DMARDs. Chest radiographs were performed for all patients; the results were considered normal if no abnormal changes were reported by the radiologists, who were blinded to the study conditions. The bacillus Calmette-Guérin vaccination status was documented if available. Patients were regularly followed up after the initiation of b/tsDMARDs; any development of active TB was recorded. Tuberculosis was defined by the 10th revision of the International Classification of Diseases, Clinical Modification (code A15-A19). All cases were confirmed by positive cultures or diagnostic pathological findings on tissue biopsy.

\section{Tuberculin skin test and interferon gamma release assay protocols}

Tuberculin skin tests were performed by rheumatologists in the out-patient clinic. Either $0.1 \mathrm{~mL}$ (two tuberculin units) of Purified Protein Derivative (PPD)-RT23 (AJ Vaccines, Demark) or $0.1 \mathrm{~mL}$ (five tuberculin units) of PPD-S (JHP Pharmaceuticals, US) were injected intradermally to the forearms. ${ }^{14}$ The maximal transverse diameter of the induration was measured at 48 hours after injection. The test was regarded as positive if it was $\geq 10 \mathrm{~mm}$, as recommended in local guidelines. ${ }^{10}$ If the area of induration was between $5 \mathrm{~mm}$ and $9 \mathrm{~mm}$ in patients on high-dose immunosuppressants, the test result was considered positive at the discretion of the treating rheumatologists. For patients who underwent the IGRA test, the following data were recorded: type of assay used, test results (positive, negative, or indeterminate), and test values if available. Two types of assays were used during the study period: the QuantiFERON-TB Gold (Qiagen, Germany) and A.TB IGRA (Haikou VTI Biological Institute, China).

\section{Latent tuberculosis infection treatment}

Patients received isoniazid $300 \mathrm{mg}$ daily for 9 months if they tested positive for LTBI. For patients with contra-indications or intolerance to isoniazid, rifampicin was used (450 mg daily for 4 months). ${ }^{10}$ Adverse events and early termination of drugs were recorded. Drug-induced liver toxicity was defined as an increase in alanine aminotransferase 5 times greater than the upper limit of normal in asymptomatic individuals, or 3 times greater than the upper limit of normal in symptomatic individuals.

\section{Study outcomes}

The primary outcome of this study was the incidence of $\mathrm{TB}$ during $\mathrm{b} / \mathrm{tsDMARD}$ therapy in the single testing and dual testing groups. Secondary outcomes included factors associated with TB, agreement between the TST and IGRA results, and the safety of LTBI treatment.

\section{Statistical analysis}

Descriptive data are presented as frequencies, means with standard deviations, or medians with ranges, as appropriate. Comparisons between clinical variables were performed using the Chi squared test or Fisher's exact test for categorical variables, independentsamples $t$ test for normally distributed continuous variables, or Mann-Whitney $U$ test for nonnormally distributed continuous variables. Survival analysis with the log rank test was used to control for differences in follow-up duration. Independent variables associated with the development of TB were identified by Cox regression modelling. Results were considered statistically significant if $\mathrm{P}<0.05$. Agreement between the TST and IGRA results was evaluated by Cohen's weighted kappa statistic. Kappa values represented the following degrees of agreement: $>0.6$, substantial agreement; 0.41 to 0.60 , moderate agreement; 0.21 to 0.40 , fair agreement; and $<0.21$, slight agreement.

\section{Results}

In total, 248 patients were screened for eligibility. Thirty one patients were excluded from this study: 26 had incomplete TST or IGRA results, and five were lost to follow-up. Ultimately, 217 patients were included in the study: 121 in the single testing group and 96 in the dual testing group. The mean patient age was 53.2 years (standard deviation, 14.0 years), and $65 \%$ of included patients were women. Most patients had rheumatoid arthritis (56.7\%), spondyloarthropathy (28.6\%), or psoriatic arthritis (11.5\%). Nearly half of the included patients (48.8\%) were receiving prednisolone. Baseline clinical data were generally similar between the two groups; however, a significantly longer mean follow-up duration was observed after initiation of $\mathrm{b} / \mathrm{tsDMARDs}$ in the single testing group $(\mathrm{P}<0.001)$, as shown in Table 1 . The use of various $b / t s D M A R D s$ is also summarised in Table 1 . Significantly more patients in the single testing group had ever been exposed to infliximab $(\mathrm{P}<0.001)$, whereas tofacitinib had been used more frequently in the dual testing group $(\mathrm{P}=0.021)$.

The frequencies of positive TST and IGRA test results in the single testing and dual testing groups are shown in Table 2. Two patients in the dual testing group had an inconclusive IGRA result. Isoniazid (28.9\%) was administered less often in the 
TABLE I. Baseline demographic data of patients in single testing and dual testing groups*

\begin{tabular}{|c|c|c|c|}
\hline Demographic data & $\begin{array}{l}\text { Single testing } \\
\text { group }(n=121)\end{array}$ & $\begin{array}{l}\text { Dual testing } \\
\text { group }(n=96)\end{array}$ & $P$ value \\
\hline Age (years) & $53.43 \pm 13.92$ & $52.98 \pm 14.2$ & 0.393 \\
\hline Sex & & & 0.914 \\
\hline Female & $79(65.3 \%)$ & $62(64.6 \%)$ & \\
\hline Male & 42 (34.7\%) & 34 (35.4\%) & \\
\hline Diagnosis & & & 0.335 \\
\hline Rheumatoid arthritis & $69(57 \%)$ & $54(56.3 \%)$ & \\
\hline Spondyloarthropathy & 37 (30.6\%) & $25(26.0 \%)$ & \\
\hline Psoriatic arthritis & $13(10.7 \%)$ & $12(12.5 \%)$ & \\
\hline Behçet's disease & $2(1.7 \%)$ & $1(1.0 \%)$ & \\
\hline Dermatomyositis & - & $3(3.1 \%)$ & \\
\hline Still's disease & - & $1(1.0 \%)$ & \\
\hline Co-morbidities & & & 0.309 \\
\hline Nil & $76(62.8 \%)$ & $56(58.3 \%)$ & \\
\hline 1 & $34(28.1 \%)$ & $36(37.5 \%)$ & \\
\hline$\geq 2$ & $11(9.1 \%)$ & $4(4.2 \%)$ & \\
\hline \multicolumn{4}{|l|}{ Baseline immunosuppressants } \\
\hline \multicolumn{4}{|l|}{ Prednisolone use } \\
\hline Any dose & $56(46.2 \%)$ & $50(52.1 \%)$ & 0.396 \\
\hline$\geq 10$ mg/day & $17(14.0 \%)$ & $18(18.8 \%)$ & 0.350 \\
\hline Methotrexate & $62(51.2 \%)$ & $53(55.2 \%)$ & 0.561 \\
\hline Sulfasalazine & $51(42.1 \%)$ & $39(40.6 \%)$ & 0.821 \\
\hline Hydroxychloroquine & $14(11.6 \%)$ & $19(19.8 \%)$ & 0.094 \\
\hline Leflunomide & $31(25.6 \%)$ & $28(29.2 \%)$ & 0.860 \\
\hline Azathioprine & $2(1.7 \%)$ & $1(1.0 \%)$ & 0.603 \\
\hline Cyclosporin A & 12 (9.9\%) & $7(7.3 \%)$ & 0.603 \\
\hline $\begin{array}{l}\text { Follow-up duration after } \\
\text { initiation of therapy (months) }\end{array}$ & $72.2 \pm 35.5$ & $38.7 \pm 28.0$ & $<0.001$ \\
\hline Chest X-ray (normal) & $101(83.5 \%)$ & $75(78.1 \%)$ & 0.318 \\
\hline \multicolumn{4}{|l|}{$\begin{array}{l}\text { Course of biologic agents ever } \\
\text { received }\end{array}$} \\
\hline Infliximab & $27(22.3 \%)$ & $2(2.1 \%)$ & $<0.001$ \\
\hline Golimumab & $32(26.4 \%)$ & $21(21.9 \%)$ & 0.436 \\
\hline Adalimumab & $32(26.4 \%)$ & $20(20.8 \%)$ & 0.336 \\
\hline Etanercept & $47(38.8 \%)$ & $40(41.7 \%)$ & 0.673 \\
\hline Certolizumab & $3(2.5 \%)$ & $3(3.1 \%)$ & 0.773 \\
\hline Tocilizumab & 27 (22.3\%) & $13(13.5 \%)$ & 0.098 \\
\hline Tofacitinib & $9(7.4 \%)$ & $17(17.7 \%)$ & 0.021 \\
\hline Abatacept & 15 (12.4\%) & $9(9.4 \%)$ & 0.481 \\
\hline Rituximab & $4(3.3 \%)$ & $3(3.1 \%)$ & 0.940 \\
\hline Secukinumab & $2(1.7 \%)$ & $6(6.3 \%)$ & 0.074 \\
\hline Ustekinumab & $1(0.8 \%)$ & $1(1.0 \%)$ & 0.869 \\
\hline
\end{tabular}

* Data are shown as mean \pm standard deviation or No. (\%), unless otherwise specified single testing group than in the dual testing group $(\mathrm{P}=0.007)$. For the primary outcome, 10 of 217 (4.6\%) patients developed TB during the followup. Significantly more patients in the single testing group developed TB, compared with patients in the dual test group ( $\mathrm{P}=0.045$; Table 2$)$. However, the difference was not statistically significant when the follow-up duration was considered, using KaplanMeier analysis and log rank test $(\mathrm{P}=0.059)$ [Fig].

Of the 10 patients who developed TB during b/tsDMARD treatment, three had extrapulmonary or disseminated TB (Table 3). The median time from the initiation of $b /$ tsDMARDs to the development of TB was 12.5 months (range, 2-32 months); five cases were diagnosed within the first 12 months. The indications for $\mathrm{b} / \mathrm{tsDMARDs}$ in these patients were rheumatoid arthritis (five patients), spondyloarthropathy (three patients), psoriatic arthritis (one patient), and Behçet's disease (one patient). Age at diagnosis of TB ranged from 23 to 73 years; the median age was 61 years. Among the nine patients who developed TB in the single testing group, eight underwent TST assessment for LTBI screening, while one underwent IGRA assessment. Eight of the nine patients had negative screening test results; one patient had positive TST results and was then administered isoniazid. However, that patient had abnormal liver function test results during treatment; thus, isoniazid was switched to rifampicin. The patient then developed pulmonary TB with TB lymphadenopathy and TB psoas abscess after 32 months of treatment with infliximab. Among the seven patients who had negative TST results in the single testing group, four had borderline TST results (area of induration, 6-9 $\mathrm{mm}$ ); three had spondyloarthropathy and were receiving sulfasalazine alone before LTBI screening, whereas the remaining patient had rheumatoid arthritis and was receiving a combination of methotrexate and leflunomide. Regarding exposure to different b/tsDMARDs among patients with $\mathrm{TB}$, nine had ever received anti-TNF- $\alpha$ treatment. The numbers of courses of $\mathrm{b} / \mathrm{tsDMARDs}$ ever received and patients who ultimately developed TB are shown in Table 4. Among these $b / t s D M A R D s$, only infliximab was significantly associated with development of $\mathrm{TB}$ $(\mathrm{P}<0.001)$. Cox regression analysis revealed that the use of infliximab was an independent predictor of TB (hazard ratio, 4.17; $\mathrm{P}=0.032$; Table 5).

Levels of agreement between the TST and IGRA were calculated in subgroups of patients who received both tests and had definitive results (Table 6). Of the 94 patients, 24 (25\%) had a discordant result: 18 had positive TST but negative IGRA results, while six had positive IGRA but negative TST results. The Cohen's kappa value was 0.413 (moderate agreement); it decreased to 0.378 (fair agreement) in patients receiving any dose of prednisolone at 
baseline, and decreased further to 0.346 in patients receiving daily prednisolone $\geq 10 \mathrm{mg}$ at the time of screening. Among traditional DMARDs used at the time of screening, leflunomide exhibited the lowest level of concordance (Cohen's kappa $=0.172$ ).

In terms of adverse events, no mortality or major morbidity were observed in relation to isoniazid treatment. Three patients $(2.4 \%)$ in the single testing group and five patients $(5.2 \%)$ in the dual testing group required early termination of isoniazid; this termination was most commonly related to abnormal liver function test results, which were reversible after discontinuation of isoniazid. Two cases of allergy to isoniazid were noted in the single testing group, while one case of suspected isoniazid-induced lupus was noted in the dual testing group. There were no statistically significant between-group differences in side-effect profiles and rates of early termination of isoniazid therapy.

\section{Discussion}

Tuberculosis remains a major complication related to use of b/tsDMARDs. Vigilant LTBI screening is needed to reduce the risk of TB reactivation. The overall prevalence of LTBI was $36.4 \%$ in this study; the test positivity rates of TST and IGRA across both groups were $33.6 \%$ and $22.5 \%$, respectively. To the best of our knowledge, no local data are available regarding the prevalence of LTBI, because medical practitioners in Hong Kong are not required to report cases of LTBI. The estimated global burden of LTBI is $23.0 \%$, although the prevalence of LTBI is expected to be higher in Asia. ${ }^{21}$
TABLE 2. Comparison of outcomes between single testing and dual testing groups*

\begin{tabular}{lccc}
\hline Outcome & $\begin{array}{c}\text { Single testing } \\
\text { group }(\mathbf{n = 1 2 1})\end{array}$ & $\begin{array}{c}\text { Dual testing } \\
\text { group }(\mathbf{n}=\mathbf{9 6})\end{array}$ & P value \\
\hline Positive TST & $35 / 115(30.4 \%)$ & $36(37.5 \%)$ & \\
Positive IGRA & $0 / 6$ & $23(24.0 \%)$ & \\
$\begin{array}{l}\text { Latent tuberculosis infection } \\
\text { treatment }\end{array}$ & $35(28.9 \%)$ & $44(45.8 \%)$ & 0.007 \\
Tuberculosis & $9(7.4 \%)$ & $1(1.0 \%)$ & 0.04 \\
\hline
\end{tabular}

Abbreviations: IGRA = interferon gamma release assay;TST = tuberculin skin test

* Data are shown as No. (\%), unless otherwise specified

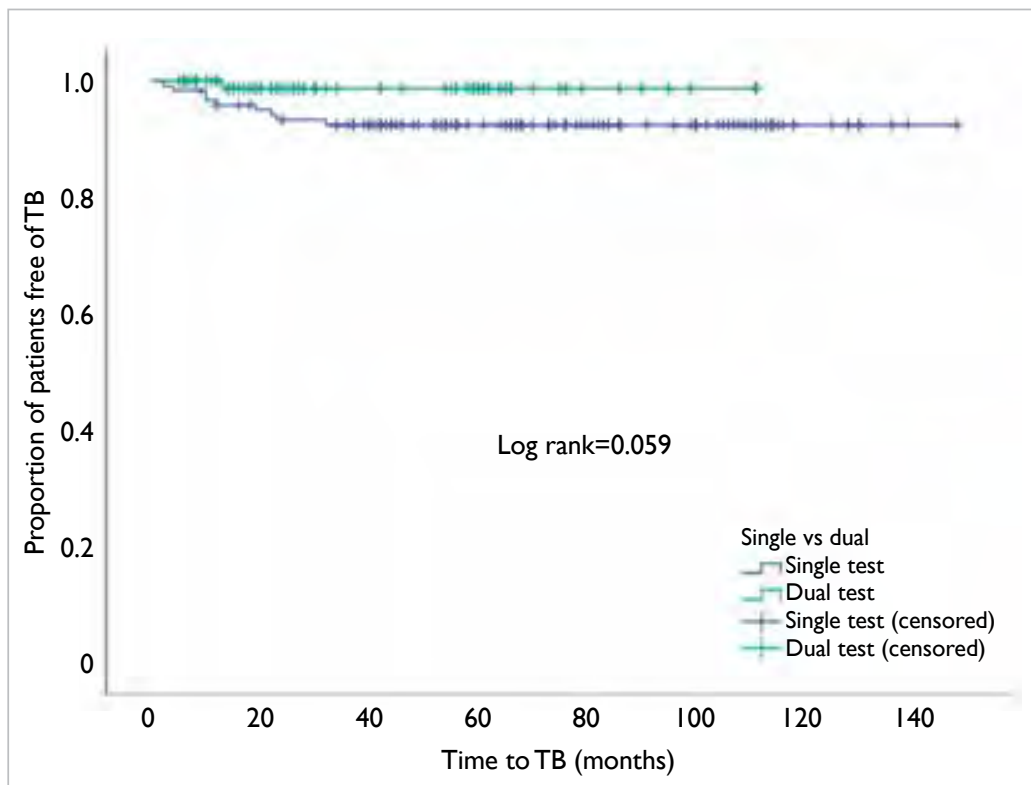

FIG. Kaplan-Meier analysis of the development of tuberculosis (TB)

TABLE 3. Summary table of cases of tuberculosis among patients with rheumatic diseases receiving b/tsDMARDs

\begin{tabular}{|c|c|c|c|c|c|c|}
\hline $\begin{array}{l}\text { Sex/age } \\
\text { (years) }\end{array}$ & Diagnosis & Site of tuberculosis & $\begin{array}{l}\text { Screening } \\
\text { result }\end{array}$ & $\begin{array}{l}\text { Drugs at time of } \\
\text { screening }\end{array}$ & $\begin{array}{l}\text { b/tsDMARDs } \\
\text { received }\end{array}$ & $\begin{array}{l}\text { Time from } \\
\text { start of } \\
\text { treatment } \\
\text { to TB onset }\end{array}$ \\
\hline Female/59 & Rheumatoid arthritis & Pulmonary & TST $2 \mathrm{~mm}$ & Prednisolone, methotrexate & Infliximab, tocilizumab & 10 Months \\
\hline Female/65 & Rheumatoid arthritis & $\begin{array}{l}\text { Pulmonary, lymph } \\
\text { node, psoas abscess }\end{array}$ & $\begin{array}{l}\text { TST } 10 \mathrm{~mm} \\
\text { (treated with } \\
\text { INAH) }\end{array}$ & $\begin{array}{l}\text { Hydroxychloroquine, } \\
\text { cyclosporin A }\end{array}$ & Infliximab & 32 Months \\
\hline Female/55 & Rheumatoid arthritis & $\begin{array}{l}\text { Gastrointestinal, } \\
\text { urinary }\end{array}$ & TST -ve & Prednisolone, leflunomide & Etanercept & 22 Months \\
\hline Female/25 & Spondyloarthropathy & Pulmonary & TST $6 \mathrm{~mm}$ & Sulfasalazine & Etanercept, golimumab & 19 Months \\
\hline Male/28 & Spondyloarthropathy & Miliary & TST $9 \mathrm{~mm}$ & Sulfasalazine & Infliximab & 2 Months \\
\hline Female/61 & Rheumatoid arthritis & Pulmonary & TST $6 \mathrm{~mm}$ & Methotrexate, leflunomide & Infliximab, tocilizumab & 23 Months \\
\hline Male/73 & Behçet's disease & Pulmonary & TST $3 \mathrm{~mm}$ & Prednisolone, methotrexate & Etanercept, infliximab & 4 Months \\
\hline Male/51 & Spondyloarthropathy & Pulmonary & TST $7 \mathrm{~mm}$ & Sulfasalazine & Etanercept, golimumab & 12 Months \\
\hline Female/67 & Rheumatoid arthritis & Pulmonary & IGRA -ve & $\begin{array}{l}\text { Prednisolone, methotrexate, } \\
\text { hydroxychloroquine }\end{array}$ & Tocilizumab, tofacitinib & 10 Months \\
\hline Male/40 & Psoriatic arthritis & Pulmonary & $\begin{array}{l}\text { TST } 0 \mathrm{~mm} \text {, } \\
\text { IGRA -ve }\end{array}$ & Nil & Adalimumab & 13 Months \\
\hline
\end{tabular}

Abbreviations: b/tsDMARDs = biologic and targeted synthetic disease-modifying antirheumatic drugs; IGRA = interferon gamma release assay; INAH = isoniazid; TB = tuberculosis; TST = tuberculin skin test 
TABLE 4. Incidences of TB associated with b/tsDMARD treatment

\begin{tabular}{lccc}
\hline $\begin{array}{l}\text { Biologic ever } \\
\text { received }\end{array}$ & $\begin{array}{c}\text { No. of } \\
\text { courses ever } \\
\text { received }\end{array}$ & $\begin{array}{c}\text { No. of patients } \\
\text { who ultimately } \\
\text { developed } \\
\text { tuberculosis }\end{array}$ & P value \\
\hline Infliximab & 29 & 5 & $<0.001$ \\
\hline Golimumab & 53 & 2 & 0.739 \\
\hline Adalimumab & 52 & 1 & 0.290 \\
\hline Etanercept & 87 & 4 & 0.995 \\
\hline Certolizumab & 6 & 0 & 0.585 \\
\hline Tocilizumab & 40 & 2 & 0.896 \\
\hline Tofacitinib & 26 & 1 & 0.843 \\
\hline Abatacept & 24 & 0 & 0.254 \\
\hline Rituximab & 7 & 0 & 0.554 \\
\hline Secukinumab & 8 & 0 & 0.526 \\
\hline Ustekinumab & 2 & 0 & 0.755 \\
\hline
\end{tabular}

Abbreviations: b/tsDMARDs = biologic and targeted synthetic disease-modifying antirheumatic drugs; TB = tuberculosis

TABLE 5. Multivariate Cox regression analysis for development of tuberculosis

\begin{tabular}{lccl}
\hline Clinical variable & $\begin{array}{c}\text { Hazard } \\
\text { ratio }\end{array}$ & $\begin{array}{c}\text { 95\% Confidence } \\
\text { interval }\end{array}$ & P value \\
\hline Age & 0.981 & $0.938-1.027$ & 0.407 \\
Steroid use & 0.444 & $0.111-1.773$ & 0.25 \\
\hline Tofacitinib use & 1.425 & $0.175-1.163$ & 0.741 \\
\hline Infliximab use & 4.167 & $1.133-15.38$ & 0.032 \\
\hline Dual screening test & 0.288 & $0.033-2.5$ & 0.259 \\
\hline
\end{tabular}

A significantly lower incidence of TB was observed in the dual testing group, which indicates that the dual test approach may be useful for prevention of $\mathrm{TB}$ during $\mathrm{b} / \mathrm{tsDMARD}$ therapy, especially in TB endemic areas such as Hong Kong. The majority of patients in the single testing group underwent TST assessment alone. The number of IGRA-only cases in the single testing group was small; however, after 10 months of b/tsDMARD treatment, TB developed in one patient who had undergone IGRA alone. This patient was receiving prednisolone, methotrexate, and hydroxychloroquine at the time of screening; these results suggest that screening with the IGRA alone might exhibit reduced sensitivity in immunosuppressed patients. Indeed, a dual LTBI screening strategy with the TST and IGRA is described in different national guidelines. ${ }^{9,22}$

Nine of 10 patients with TB had received anti-TNF- $\alpha$ treatment before the development of TB. Multivariate analysis revealed that the use of infliximab was significantly associated with the development of TB. This association between use of infliximab and development of TB is consistent with the findings in a previous observational study in the United States. ${ }^{23,24}$ Previous studies assessing the associations of $\mathrm{TB}$ with infliximab, adalimumab, and etanercept also found higher TB incidence rates when patients received infliximab or adalimumab, compared with etanercept. ${ }^{25,26}$ The specific mechanisms underlying these differences in TB risk associated with the use of different antiTNF agents are not fully understood. However, the differences may be related to the methods by which these agents neutralise TNF- $\alpha$. Infliximab is a chimeric monoclonal antibody against TNF- $\alpha$, which targets both soluble and membrane-bound forms of TNF- $\alpha$. Similar binding activities are also

TABLE 6. TST and IGRA results in the dual testing group

\begin{tabular}{|c|c|c|c|c|c|c|}
\hline & \multicolumn{4}{|c|}{ No. $(\%)$ of patients } & \multirow{2}{*}{$\begin{array}{c}\text { Kappa value } \\
\text { (standard } \\
\text { deviation) }\end{array}$} & \multirow{2}{*}{$\begin{array}{l}\text { Level of } \\
\text { agreement }\end{array}$} \\
\hline & TST+/IGRA+ & TST-/ IGRA+ & TST+/IGRA- & TST-/IGRA- & & \\
\hline All patients $(n=94)$ & $17(18.1 \%)$ & $6(6.4 \%)$ & $18(19.1 \%)$ & $53(56.4 \%)$ & $0.413(0.096)$ & Moderate \\
\hline $\begin{array}{l}\text { Patients receiving any dose of } \\
\text { prednisolone }(n=49)\end{array}$ & $6(12.2 \%)$ & $4(8.2 \%)$ & $7(14.3 \%)$ & $32(65.3 \%)$ & $0.378(0.152)$ & Fair \\
\hline $\begin{array}{l}\text { Patients receiving prednisolone } \geq 10 \mathrm{mg} \\
\text { daily }(n=17)\end{array}$ & $2(11.8 \%)$ & $2(11.8 \%)$ & $2(11.8 \%)$ & $11(64.7 \%)$ & $0.346(0.263)$ & Fair \\
\hline Patients not receiving prednisolone $(n=45)$ & $11(24.4 \%)$ & $2(4.4 \%)$ & $11(24.4 \%)$ & $21(46.7 \%)$ & $0.417(0.125)$ & Moderate \\
\hline Patients receiving methotrexate $(n=53)$ & $9(17.0 \%)$ & $3(5.7 \%)$ & $9(17.0 \%)$ & $32(60.4 \%)$ & $0.451(0.130)$ & Moderate \\
\hline Patients receiving sulfasalazine $(n=39)$ & $11(28.2 \%)$ & $3(7.7 \%)$ & $4(10.3 \%)$ & $21(53.8 \%)$ & $0.616(0.131)$ & Substantial \\
\hline $\begin{array}{l}\text { Patients receiving hydroxychloroquine } \\
(\mathrm{n}=19)\end{array}$ & $4(21.1 \%)$ & $1(5.3 \%)$ & $2(10.5 \%)$ & $12(63.2 \%)$ & $0.617(0.198)$ & Substantial \\
\hline Patients receiving leflunomide $(n=28)$ & $3(10.7 \%)$ & $2(7.1 \%)$ & $8(28.6 \%)$ & $15(53.6 \%)$ & $0.172(0.170)$ & Slight \\
\hline
\end{tabular}

Abbreviations: IGRA = interferon gamma release assay; TST = tuberculin skin test 
exhibited by adalimumab and golimumab, which are both monoclonal antibodies against TNF- $\alpha$. In contrast, etanercept is a fusion protein of the TNF- $\alpha$ receptor and human immunoglobulin G1 antibody, which has a much lower cytotoxicity for membranebound TNF- $\alpha$ expressing cells. ${ }^{27}$ An alternative explanation is that infliximab and adalimumab cause greater reduction in TB-responsive CD4 cells and suppression of antigen-induced interferon gamma production, when compared with etanercept; these results were demonstrated in a previous in-vitro study. ${ }^{28}$

In our study, the median time from initiation of b/tsDMARD treatment to the development of TB was 12.5 months, which differed from the median of 14 weeks reported by Keane et al. ${ }^{24}$ However, the majority of cases included in the report by Keane et $\mathrm{al}^{24}$ were from countries with low TB incidence, whereas TB is endemic in Hong Kong. Importantly, in Hong Kong, development of TB could result from reactivation of LTBI or from new TB infection. Therefore, it is important for rheumatologists to remain vigilant regarding the development of $\mathrm{TB}$ in all patients receiving $b / t s D M A R D s$, regardless of the duration of $\mathrm{b} / \mathrm{tsDMARD}$ treatment. Patients should receive education regarding possible symptoms associated with $\mathrm{TB}$, and should be encouraged to seek medical attention when such symptoms arise. Regular chest X-ray surveillance should also be performed.

The level of agreement between the IGRA and TST was moderate in this study; discordant results were more commonly observed in patients receiving prednisolone or leflunomide at the time of screening. An immunosuppressed state has been suggested to induce a depressed $\mathrm{T}$ cell response, which may affect the accuracy of the tests; notably, a systematic review showed that both IGRA and TST results were significantly influenced by immunosuppressive therapy. ${ }^{29}$ In Hong Kong, local guidelines recommend a cut-off value of $10 \mathrm{~mm}$ for a positive TST result, whereas some experts recommend lowering the cut-off value to $5 \mathrm{~mm}$ in patients receiving highdose prednisolone and/or immunosuppressants. Among the seven patients with $\mathrm{TB}$ in the single testing group, four had borderline TST results (area of induration, 6-9 mm). Unfortunately, we did not re-examine the results later (ie, at 72 hours), which might have enabled us to identify patients with delayed tuberculin response. Thus, TST sensitivity might have been impaired. Furthermore, both tests exhibit other limitations. The TST requires an intradermal injection and induration assessment, both of which are highly operator-dependent. The IGRA can yield a confusing indeterminate result in a considerable number of patients. Therefore, although universal dual testing might be difficult due to limited resources, its use should be strongly considered in select groups of patients. In patients with borderline TST results, additional IGRA testing might be helpful. Similarly, TST assessment should be considered if IGRA results are indeterminate.

Our study had a few limitations. First, the median follow-up duration was significantly longer in the single testing group. Notably, the incidence of TB during b/tsDMARD therapy was not significantly different between groups when the follow-up duration was considered, indicating that follow-up duration was an important confounder. The IGRA was only introduced in our centre in August 2013; all patients who began b/tsDMARD therapy before August 2013 only underwent single testing with the TST, which led to a longer follow-up duration in the single testing group. However, the risk of TB reactivation was highest in the first 90 days after initiation of b/tsDMARD therapy ${ }^{23}$; in the current study, the median follow-up duration of 27.5 months in the dual testing group was presumably sufficient to assess patients during that period. Second, there was a disproportionately high rate of infliximab use in the single testing group, compared with the dual group, such that infliximab use constituted an important confounder. Because of the retrospective nature of this study, all patients underwent TST assessment alone before August 2013, and infliximab was one of the first biologic agents available; this sequence of events is likely to explain the higher usage of infliximab in the single testing group. Third, the number of IGRA-only patients in this study was relatively small; therefore, we could not draw robust conclusions regarding the reliability of LTBI screening by IGRA alone, compared with dual testing. However, among the six patients who underwent IGRA assessment alone, one developed TB after 10 months of sequential tocilizumab and tofacitinib treatment, despite an initial negative screening result. Further multicentre prospective studies are needed to compare the efficacy and safety of either TST or IGRA alone with dual testing, in terms of preventing the development of TB during b/tsDMARD treatment. Lastly, some patients on immunosuppressants underwent TST assessment and exhibited borderline area of induration; these test results might have been regarded as positive at the discretion of the attending rheumatologists. The lack of a clear definition might have constituted another source of bias.

\section{Conclusion}

Although the difference in follow-up duration may have been a confounding factor, the results of this study suggest that dual LTBI screening with the TST and IGRA might be a useful and safe strategy to reduce the incidence of TB in patients with rheumatic diseases receiving $b / t s D M A R D s$ in an endemic area. 
Use of infliximab was significantly associated with development of TB. The level of agreement between the TST and IGRA was moderate; it was lower in patients receiving prednisolone or leflunomide at time of LTBI screening. Dual LTBI screening should be strongly considered in patients with rheumatic diseases receiving steroid or leflunomide treatment at the time of LTBI screening, when either test result is equivocal, or when use of infliximab is anticipated.

\section{Author contributions}

All authors had full access to the data, contributed to the study, approved the final version for publication, and take responsibility for its accuracy and integrity.

Concept or design: I Tang, H So, R Yip.

Acquisition of data: I Tang, H So, L Luk, V Wong, S Pang, V Lao.

Analysis or interpretation of data: I Tang, H So, L Luk, V Wong, S Pang, V Lao.

Drafting of the manuscript: I Tang, H So.

Critical revision of the manuscript for important intellectual content: L Luk, V Wong, S Pang, V Lao, R Yip.

\section{Conflicts of interest}

All authors have disclosed no conflicts of interest.

\section{Declaration}

This research was presented in the Hong Kong Hospital Authority Convention 2019, East Asian Group of Rheumatology 2019 and Annual Meeting of American College of Rheumatology 2019.

\section{Funding/support}

This research received no specific grant from any funding agency in the public, commercial, or not-for-profit sectors.

\section{Ethics approval}

This study conformed to the provisions of the Declaration of Helsinki and was approved by the Hospital Authority Research Ethics Committee (Kowloon Central/Kowloon East) (Ref KC/KE-19-0241/ER-3). The requirement for patient consent was waived by the ethics committee. The study contains no identifiable personal or medical information.

\section{References}

1. Gómez-Reino JJ, Carmona L, Valverde VR, Mola EM, Montero MD; BIOBADASER Group. Treatment of rheumatoid arthritis with tumor necrosis factor inhibitors may predispose to significant increase in tuberculosis risk: a multicenter active-surveillance report. Arthritis Rheum 2003;48:2122-7.

2. Winthrop KL, Baxter R, Liu L, et al. Mycobacterial diseases and antitumour necrosis factor therapy in USA. Ann Rheum Dis 2013;72:37-42.

3. Ridker PM, Everett BM, Thuren T, et al. Antiinflammatory therapy with canakinumab for atherosclerotic disease. N Engl J Med 2017;377:1119-31.

4. Winthrop KL, Mariette X, Silva JT, et al. ESCMID Study Group for Infections in Compromised Hosts (ESGICH)
Consensus Document on the safety of targeted and biological therapies: an infectious diseases perspective (Soluble immune effector molecules [II]: agents targeting interleukins, immunoglobulins and complement factors). Clin Microbiol Infect 2018;24 Suppl 2:S21-40.

5. Kourbeti IS, Ziakas PD, Mylonakis E. Biologic therapies in rheumatoid arthritis and the risk of opportunistic infections: a meta-analysis. Clin Infect Dis 2014;58:1649-57.

6. Koike T, Harigai M, Inokuma S, et al. Effectiveness and safety of tocilizumab: postmarketing surveillance of 7901 patients with rheumatoid arthritis in Japan. J Rheumatol 2014;41:15-23.

7. Hasan T, Au E, Chen S, Tong A, Wong G. Screening and prevention for latent tuberculosis in immunosuppressed patients at risk for tuberculosis: a systematic review of clinical practice guidelines. BMJ Open 2018;8:e022445.

8. Chen DY, Su WJ, Shen GH, et al. 2012 Screening and management of tuberculosis infection in patients scheduled for tumor necrosis factor-alpha inhibitors: consensus recommendations from the Taiwan Rheumatology Association. Formos J Rheumatol 2012;26:8-14.

9. Mazurek GH, Jereb J, Vernon A, et al. Updated guidelines for using interferon gamma release assays to detect Mycobacterium tuberculosis infection-United States, 2010. MMWR Recomm Rep 2010;59:1-25.

10. Lau CS, Chia F, Dans L, et al. 2018 Update of the APLAR recommendations for treatment of rheumatoid arthritis. Int J Rheum Dis 2019;22:357-75.

11. Kleinert S, Tony HP, Krueger K, et al. Screening for latent tuberculosis infection: performance of tuberculin skin test and interferon-gamma release assays under real-life conditions. Ann Rheum Dis 2012;71:1791-5.

12. Bartalesi F, Vicidomini S, Goletti D, et al. QuantiFERONTB Gold and the TST are both useful for latent tuberculosis infection screening in autoimmune diseases. Eur Respir J 2009;33:586-93.

13. Ruan Q, Zhang S, Ai J, Shao L, Zhang W. Screening of latent tuberculosis infection by interferon- $\gamma$ release assays in rheumatic patients: a systemic review and meta-analysis. Clin Rheumatol 2016;35:417-25.

14. So H, Yuen CS, Yip RM. Comparison of a commercial interferon-gamma release assay and tuberculin skin test for the detection of latent tuberculosis infection in Hong Kong arthritis patients who are candidates for biologic agents. Hong Kong Med J 2017;23:246-50.

15. Aletaha D, Neogi T, Silman AJ, et al. 2010 Rheumatoid arthritis classification criteria: an American College of Rheumatology/European League Against Rheumatism collaborative initiative. Ann Rheum Dis 2010;69:1580-8.

16. Tillett W, Costa L, Jadon D, et al. The ClASsification for Psoriatic ARthritis (CASPAR) Criteria-a retrospective feasibility, sensitivity, and specificity study. J Rheumatol 2012;39:154-6.

17. Rudwaleit M, van der Heijde D, Landewé $R$, et al. The Assessment of SpondyloArthritis International Society classification criteria for peripheral spondyloarthritis and for spondyloarthritis in general. Ann Rheum Dis 2011;70:25-31.

18. International Study Group for Behçet's Disease. Criteria for diagnosis of Behçet's disease. Lancet 1990;335:1078-80.

19. Yamaguchi M, Ohta A, Tsunematsu T, et al. Preliminary criteria for classification of adult Still's disease. J Rheumatol 1992;19:424-30. 
20. Bohan A, Peter JB. Polymyositis and dermatomyositis (first of two parts). N Engl J Med 1975;292:344-7.

21. Houben RM, Dodd PJ. The global burden of latent tuberculosis infection: a re-estimation using mathematical modelling. PLoS Med 2016;13:e1002152.

22. Cantini F, Nannini C, Niccoli L, et al. Guidance for the management of patients with latent tuberculosis infection requiring biologic therapy in rheumatology and dermatology clinical practice. Autoimmun Rev 2015;14:503-9.

23. Wallis RS, Broder MS, Wong JY, Hanson ME, Beenhouwer DO. Granulomatous infectious diseases associated with tumor necrosis factor antagonists. Clin Infect Dis 2004;38:1261-5.

24. Keane J, Gershon S, Wise RP, et al. Tuberculosis associated with infliximab, a tumor necrosis factor alpha-neutralizing agent. N Engl J Med 2001;345:1098-104.

25. Navarra SV, Tang B, Lu L, et al. Risk of tuberculosis with anti-tumor necrosis factor- $\alpha$ therapy: substantially higher number of patients at risk in Asia. Int J Rheum Dis
2014;17:291-8.

26. Yamauchi PS, Bissonnette R, Teixeira HD, Valdecantos WC. Systematic review of efficacy of anti-tumor necrosis factor (TNF) therapy in patients with psoriasis previously treated with a different anti-TNF agent. J Am Acad Dermatol 2016;75:612-8.

27. Baddley JW, Cantini F, Goletti D, et al. ESCMID Study Group for Infections in Compromised Hosts (ESGICH) Consensus Document on the safety of targeted and biological therapies: an infectious diseases perspective (Soluble immune effector molecules [I]: anti-tumor necrosis factor- $\alpha$ agents). Clin Microbiol Infect 2018;24 Suppl 2:S10-20.

28. Saliu OY, Sofer C, Stein DS, Schwander SK, Wallis RS. Tumor-necrosis-factor blockers: differential effects on mycobacterial immunity. J Infect Dis 2006;194:486-92.

29. Shahidi N, Fu YT, Qian H, Bressler B. Performance of interferon-gamma release assays in patients with inflammatory bowel disease: a systematic review and meta-analysis. Inflamm Bowel Dis 2012;18:2034-42. 